western Europe during most of the present warm period, the Holocene, and only arrived there long after conditions favourable to it were established, perhaps promoted by the introduction of agriculture and associated land-use changes. Nonclimatic shifts in the vegetation constitute a definite source of error in palaeoclimate reconstructions based on modern vegetational analogues. Control by indicator plants is therefore important. Field $e t$ al. also attempted a climate reconstruction for the Grande Pile location, about $640 \mathrm{~km}$ SSW of Bispingen and $330 \mathrm{~m}$ above sea level, which today has a MTCO of $+0.6^{\circ} \mathrm{C}$. In this reconstruction the interval with extreme winter coldness is absent. This is also the case in the palaeoclimate reconstructions based on Eemian pollen diagrams from Grande Pile by Guiot ${ }^{8}$ and Guiot et al. ${ }^{9,10}$, in which both MTCO and annual mean temperature during the whole Eemian interglacial are similar to present-day conditions. We therefore suggest that the severe winter spell during the Eemian at Bispingen proposed by Field et al. is an artefact caused by limitations in their climate reconstruction method.

\section{Bent Aaby}

\section{Henrik Tauber}

The Natural Science Research Unit,

The National Museum, Ny Vestergade 11,

DK-1471 Copenhagen K, Denmark

Huntley AND Field RePly - Aaby and Tauber assert that the North Atlantic Ocean and Norwegian Sea were "at least as warm as today" during the period of "supposed severe winter". Recent highresolution records of sea-surface temperature $^{11}$, however, show marked cooling in both areas no more than 5,000 yr after the stage $6 / 5 \mathrm{e}$ termination. In the Norwegian Sea, temperatures were similar to those of modern times during only the initial short warm period of $5 \mathrm{e}$, subsequently falling to values comparable to those during glacial stages $^{11}$. In the North Atlantic, early warm period temperatures around $1.7^{\circ} \mathrm{C}$ higher than present fell by around $2{ }^{\circ} \mathrm{C}$ at the same time ${ }^{11}$. Such a sea-surface temperature scenario is consistent with stronger mid-Eemian cooling in northern and northeastern compared with western and southern Europe and generally concurs with the mechanism we hypothesized ${ }^{1}$. Our hypothesis is also supported by evidence of sea-surface temperature instability in the North Sea during the Eemian; two marked cooling episodes are reported north of Denmark ${ }^{12}$.

Aaby and Tauber suggest that our reconstruction "is directly contradicted" by occurrences of ivy (Hedera helix L.) and holly (Ilex aquifolium L.) pollen at Bispingen and in other Eemian records, as these taxa are today found only where mean temperature of the coldest month (MTCO) is $\geq-5^{\circ} \mathrm{C}$. Careful examination of our reconstruction shows MTCO is
$-5{ }^{\circ} \mathrm{C}$ for approximately $1,500 \mathrm{yr}$ after its fall at a relative age of 7,600 yr, with only one short colder episode during this interval. This is consistent with the palynological evidence of $H$. helix and I. aquifolium. Pollen of both occurs consistently in samples during and before this 1,500-yr interval, but is represented extremely sparsely thereafter ${ }^{5}$. The isolated occurrence of both in a sample with relative age about $5,000 \mathrm{yr}$ coincides with a peak in reconstructed MTCO, the upper $95 \%$ confidence interval of which reaches $>-5{ }^{\circ} \mathrm{C}$. Given that these 'indicator' taxa were not used in our reconstruction, their pattern of occurrence provides independent support rather than contradicting our reconstruction. As to their wider occurrences in Eemian records, these can be systematically evaluated only by considering their relative spatial and temporal contexts. We make no claim that the palaeoclimate history reconstructed at Bispingen is universal; indeed, we draw attention to contrasts with sites further south and/or west.

Aaby and Tauber suggest that "the discrepancies" they identify may result from difficulties in finding appropriate analogues. Although, as we indicated ${ }^{1}$, this may apply to the more extreme cold oscillations reconstructed, the degree of analogy generally was comparable to Holocene samples. They further suggest that the absence of beech (Fagus sylvatica L.) from northern Europe during the Eemian resulted from unknown but nonclimatic factors and that the resulting difference in forest composition underlies the reconstruction of colder winters than today. While we agree with the latter conclusion, the source cited by Aaby and Tauber in support of their assertions about $F$. sylvatica ${ }^{7}$ is contradicted by recent work ${ }^{13}$ showing $F$. sylvatica occupies a very similar climatic range to that occupied in eastern North America by Fagus grandifolia Ehrh. It has never, to our knowledge, been suggested that human interference has influenced the distribution of the latter. Furthermore, Prentice et al. ${ }^{14}$ demonstrate that $F$. grandifolia maintained its range in equilibrium with climate

\footnotetext{
1. Field, H. M., Huntley, B. \& Müller, H. Nature 371, 779-783 (1994)

Dansgaard, W. et al. Nature 364, 218-220 (1993)

3. Kellogg, T. B. Boreas 9, 115-137 (1980).

4. Iversen, J. Geol. För. Stockh. Förh. 66, 463-483 (1994).

4. Müller, H. Geol. Jb. A21, 149-169 (1974).

6. Müller, H. Geol. Jb. A21, 149-169 (1974).

7. Huntley, B. \& Birks, H. J. B. An Atlas of Past and Present Pollen Maps for Europe: 0-13000 Years Ago (Cambridge Univ. Press, UK, 1983).

8. Guiot, J. Palaeogeogr. Palaeolimnol. Palaeoecol $\mathbf{8 0}$ 49-69 (1990).

9. Guiot, J. Pons, A., Beaulieu, J. L. \& Reille, H. Nature 338, 309-313 (1989)

10. Guiot, J. et al. Palaeogeogr. Palaeolim. Palaeoecol. 103, 73-93 (1992).

11. Cortijo, E. et al. Nature 372, 446-449 (1994).

12. Seidenkrantz, M.-S., Kristensen, P. \& Knudsen, K.L. J. Quat. Sci. 10, 77-82 (1995)

13. Huntley, B., Bartlein, P.J. \& Prentice, I.C. J. Biogeogr. 16, 551-560 (1989).

14. Prentice, I. C., Bartlein, P. J. \& Webb, T. III Ecology 72 , 2038-2056 (1991)

15. GRIP Members Nature 364, 203-207 (1993).

16. Thouveny, N. et al. Nature 371, 503-506 (1994).
}

throughout the Holocene. We maintain that the reconstruction of colder winter conditions at Bispingen during the latter two-thirds of the Eemian concurs with the palynological record and is the most parsimonious explanation of observed differences in forest composition between the latter parts of the Holocene and Eemian in this region. The principal features of the reconstruction are consistent with the GRIP ice core data ${ }^{15}$, and with data from ocean and shelf cores ${ }^{11,12}$. The Bispingen region is likely to experience climate changes associated with such changes in circulation and/or surface temperature in the Norwegian and North seas, although there is evidence of Eemian climate fluctuations elsewhere in Europe ${ }^{16}$. Further studies are needed to establish the extent, timing and duration of such fluctuations in different parts of the continent.

\section{Brian Huntley}

Department of Biological Sciences,

University of Durham,

Durham DH1 3LE, UK

Michael H. Field

Laboratoire de Botanique Historique et Palynologie,

Université de Droit d'Economie et des

Sciences d'Aix-Marseille, Boite 451, 13397 Marseille Cedex 13, France

\section{Lie detection}

SIR - The results obtained by $\mathrm{R}$. Wiseman on lie detection, published in Nature 373, 391; 1995, but which I read about in the April issue of Monthly Nature, must be regarded as dubious, because they were obtained in uncontrolled conditions via polls in the mass media. It is well known that the audience of every newspaper, radio or television station is different. And differences in frequency of lie detection may be the result, not of differences of cues used by observers (visual, verbal, vocal), but of differences in the proportions of skills in the different groups of readers (intelligence, perspicacity and so on).

Another possible source of large bias is the self-selection of people who responded to the request for participation. Numerous television viewers could not detect the lies, fewer Daily Telegraph readers could, but many radio listeners were able to detect the lies. This outcome is probably the result of selection, as different proportions of people in the three groups may have failed to respond out of lack of enthusiasm, being too busy and so on. The results obtained by Wiseman can be explained on this basis.

These are only two of the many possible sources of bias in an uncontrolled study of this type.

Vasily Vlassov

Department of Aerospace Medicine, Saratov Medical University,

PO Box 1528, Saratov 410601, Russia 